\title{
Pituitary tumor apoplexy: characteristics, treatment, and outcomes
}

\author{
Meg Verrees, M.D., Baha M. Arafah, M.D., and Warren R. Selman, M.D. \\ Department of Neurosurgery and Division of Endocrinology, Department of Internal Medicine, \\ Case Western Reserve University, University Hospitals of Cleveland, Cleveland, Ohio
}

\begin{abstract}
Pituitary tumor apoplexy is an uncommon event heralded by abrupt onset of severe headache, restriction of visual fields, deterioration of visual acuity, and weakness of ocular motility frequently coupled with clinical indications of decreased endocrine function. Hemorrhage into or necrosis of a preexisting sellar mass, usually a pituitary macroadenoma, produces an expansion of sellar contents. Compression of adjacent structures elicits the variable expression of symptoms referable to displacement of the optic nerves and chiasm and impingement of the third, fourth, and sixth cranial nerves. Damage to or destruction of the anterior pituitary leads to multiple acute and/or chronic hormone deficiencies in many patients. Medical management may be used in rare cases in which the signs and symptoms are mild and restricted to meningismus or ophthalmoplegia deemed to be stable. In patients with visual or oculomotor lability or an altered level of consciousness, expeditious surgical decompression, accomplished most commonly through a transsphenoidal approach, should be performed to save life and vision and to optimize the chance of regaining or maintaining pituitary function.
\end{abstract}

\section{KEY WORDS • pituitary adenoma • pituitary tumor apoplexy • pituitary apoplexy • pituitary hemorrhage • pituitary infarction • pituitary necrosis}

\section{BACKGROUND AND EPIDEMIOLOGICAL CONSIDERATIONS}

Pituitary tumor apoplexy (the second syllable of the suffix "-plexy," originating from the Greek term meaning to strike or to have a stroke) refers to the abrupt onset of a severe headache frequently coupled with nausea, vertigo, meningismus, and/or a decreased level of consciousness. ${ }^{1,3,9,14,15,19,21,65}$ Ophthalmoplegia, deterioration of visual acuity, and restriction of visual fields are also frequently encountered (Table 1). The episode is most often obvious and discrete, but may have a more subtle onset, or even be clinically silent. $15,27,40,44,47,49,53,57,80,81$

Signs and symptoms are attributed to the rapid expansion of an infarcted and/or hemorrhagic pituitary adenoma that extends laterally into the cavernous sinus or reaches superiorly to displace the optic nerves and chiasm. Computerized tomography or MR imaging indicate sellar and/ or suprasellar abnormalities that are consistent with hemorrhage and necrosis.

Bailey ${ }^{6}$ described the first case of pituitary tumor associated with hemorrhage in 1898; in 1950, Brougham and colleagues ${ }^{13}$ examined five patients and called the collection of signs and symptoms due to necrosis and/or hemorrhage "pituitary apoplexy." We believe that the term "pituitary tumor apoplexy" is more suitable because the

Abbreviations used in this paper: $\mathrm{CSF}=$ cerebrospinal fluid; $\mathrm{CT}=$ computerized tomography; $\mathrm{DI}=$ diabetes insipidus; IHA = inferior hypophysial artery; $\mathrm{MR}=$ magnetic resonance; $\mathrm{SAH}=$ subarachnoid hemorrhage; SHA = superior hypophysial artery. syndrome is associated with a pituitary adenoma in the overwhelming number of cases and is linked with healthy glands in only a few isolated instances.

Pituitary adenomas comprise approximately $10 \%$ of intracranial tumors ${ }^{68,72}$ the reported incidence of apoplexy in these lesions ranges from $0.6^{50}$ to $27.7 \% .^{49}$ Values quoted at the high end of this range may reflect the inclusion of cases in which blood discovered during surgical or histopathological examination was obtained from specimens of asymptomatic patients. ${ }^{8,24,47,81}$ Most reports of series indicate that the incidence of apoplexy among pituitary adenomas is 2 to $7 \%$ when clinical signs coupled with surgical or histopathological evidence are considered. ${ }^{18,23,46 \text {, }}$ ${ }_{47,52,81}$ Recurrence following apoplexy is rare and has only been documented in a few cases. ${ }^{1,7,8,15,37,59}$ The clinical syndrome usually evolves from within a few hours to 3 days. ${ }^{19,42}$

All types of tumors are at similar risk for developing apoplexy. Nearly $50 \%$ of apoplectic events occur in patients who were not previously known to harbor a pituitary lesion. ${ }^{14,24,41,64}$ Men are affected more commonly than women and in some series the ratio of male to female patients is as divergent as $2: 1.8,21,24,36,59,79,83$ The age range of affected individuals stretches from the first through the eighth decade, with most cases presenting among individuals in the fifth or sixth decade. ${ }^{1,12,15,19,24,48,59,65}$

\section{PRESENTATION, DIAGNOSIS, AND PATHOPHYSIOLOGY}

Clinical unawareness of the presence of a preexisting 
TABLE 1

Signs and symptoms of pituitary tumor apoplexy

headache (frontal or retroorbital)

restriction of visual fields

decrease in visual acuity

ophthalmoplegia

nausea

vomiting

vertigo

meningismus

decreased level of consciousness

facial pain or altered or impaired facial sensation

epilepsy

fever

hemiparesis

Horner syndrome

pituitary mass often renders apoplexy an overlooked possibility; consequently, the diagnosis is often delayed and the clinical signs are mistaken as produced by a different cause. ${ }^{1,13,15,19,21,24,34,39,42,53,60,80}$ The nonspecific nature and variability of signs and symptoms further confound expeditious establishment of an appropriate diagnosis. $1,24,29,40,80$

Headache is the most commonly reported symptom and is present in up to $100 \%$ of affected patients; it is almost universally described as severe and abrupt, and located retroorbitally or bifrontally. ${ }^{8,9,15,19,21,24,53,59,65,80}$ A deterioration in visual acuity leading to blindness, visual field defects, and ophthalmoplegia are frequently associated with the ictus, as are nausea, vomiting, lethargy, meningismus, and a decreased level of consciousness. ${ }^{9,10,19,36,38,76,81} \mathrm{Al}$ tered facial sensation or facial pain, hemiparesis, seizures, or miosis and ptosis associated with Horner syndrome are less frequently encountered. ${ }^{19,24,42}$

The coupling of deficits and the general variability of signs and symptoms reflect the extension and contour of necrotic or hemorrhagic material in addition to insinuation of the mass into the cavernous sinus and the subarachnoid space. Headache occurs secondary to meningeal irritation from the presence of blood entering the basal cisterns or as a consequence of dural stretching. ${ }^{20,50,60,80,81}$ Blood gaining access to the suprasellar cistern through a dilated aperture in the diaphragma sella may provoke the development of a chemical meningitis signaled by fever, nuchal rigidity, and photophobia. ${ }^{60}$ Adrenal insufficiency provides another reasonable explanation for the pyrexia.

Distension of the optic nerves and chiasm account for restriction of visual fields, specifically bitemporal hemianopia. ${ }^{60}$ Lateral extension of hemorrhage and necrosis leads to defects in the third, fourth, fifth (first and second divisions), and sixth cranial nerves. ${ }^{60}$ The third cranial nerve is most commonly affected in isolation or combined with other nerve deficits. ${ }^{8,21,26,41,42,47,49,58,62,63,65,67,74}$ Several authors describe compression of the third nerve against the interclinoid ligament as reason for the familiar inclusion of this nerve in the grouping of symptoms or in a singular presentation. ${ }^{35,58,67,70}$ The position of the third nerve parallel to the pituitary gland in the lateral wall of the sinus may make this nerve more directly susceptible to pressure transmitted via rapid lateral expansion. ${ }^{58,68}$

Medially located within the sinus, the sixth cranial nerve is the next most frequently affected. ${ }^{47,56,65}$ The fourth cranial nerve is the least commonly involved in plural defects and it is rare for this nerve to be affected separately. Facial pain, altered facial sensation, hypesthesia, and/or loss of corneal reflex are occasionally mentioned as associated symptoms. ${ }^{13,20,58,65}$

Endocrine abnormalities associated with hypopituitarism, pressure transmitted to the brainstem, or hypothalamic compression may account for a diminished level of consciousness. ${ }^{21,70,80}$ Vasospasm due to SAH following the apoplectic event may provoke hemispheric signs. ${ }^{17}$, 25,65,80 Acute diminishment of the caliber of the intracavernous carotid artery and decreased blood flow secondary to constriction from pressure of edematous, hemorrhagic material or from being wedged against the anterior clinoid process have also been postulated as accounting for episodes of lethargy or hemiplegia. $19,25,58,60,64,65,79,80$ Cortical irritation from extension of hemorrhage into the brain parenchyma may elicit seizures. ${ }^{58}$ Encroachment on the sympathetic plexus can lead to the Horner sign. Attenuation of venous channels draining into the sinus may trigger proptosis and swelling of the eyelid.

Signs of mass effect on the optic nerves and chiasm are commonly noted at presentation in patients with pituitary adenomas (243 of 247 patients in a series conducted by Cushing), ${ }^{67}$ yet only 5 to $15 \%$ of patients with adenomas are noted to have optomotor defects. ${ }^{15,20,67,68,70}$ In contrast, although chiasmal abnormalities continue to be a prominent sign in patients with necrosis or hemorrhage, the incidence of optomotor palsies increases to 60 to $100 \%$ in these patients. ${ }^{47,70,80}$

The reason for the disparity in the frequency or pattern of occurrence between chiasmal and optokinetic signs associated with adenomas, as opposed to pituitary tumor apoplexy, has been attributed to the vulnerability of the optic nerves and chiasm to even gradual stretching, which occurs with an adenoma, compared with the relative tolerance and greater mobility of the third, fourth, and sixth cranial nerves, which are comparatively undisturbed by the more insidious effects of an adenoma. These more durable nerves frequently do not show signs of compromise unless or until they are abruptly compressed. . $^{18,34,67,80}$

The diagnosis of pituitary tumor apoplexy is frequently complicated by signs and symptoms that may resemble those of other intracranial pathological entities (Table 2). Headache, photophobia, stiff neck, and oculomotor palsy may mimic a ruptured intracranial aneurysm, ${ }^{24}$ whereas fever, meningismus, and lethargy can appear to indicate bacterial or viral meningitis. ${ }^{14,20,24,66}$ Periorbital edema from compression of the venous plexus contained in the cavernous sinus paired with defects resulting from encroachment on adjacent cranial nerves can emulate cavernous sinus thrombosis..$^{49,70}$ Unilateral ptosis and mydriasis, in addition to restriction of adduction, elevation, and downward gaze, may raise consideration of the presence of a posterior communicating artery aneurysm or, if lacking the inclusion of pupillary dilation, diabetic third nerve palsy. ${ }^{62}$

Hypopituitarism, with variably decreased levels of all or multiple pituitary hormones, is evident on presentation in the majority of patients who present with apoplexy..$^{3,19,31,59,79,80}$ This attenuation in hormone levels may 
TABLE 2

Differential diagnosis of pituitary tumor apoplexy

\author{
SAH from aneurysmal rupture \\ viral or bacterial meningitis \\ temporal arteritis \\ migraine \\ spontaneous hemorrhage (hypertensive \\ or amyloid bleeding or from a \\ metastatic tumor or primary lesion) \\ diabetic oculomotor palsy \\ optic neuritis \\ vertebrobasilar insufficiency \\ hypertensive encephalopathy \\ transtentorial herniation \\ cavernous sinus thrombosis \\ carotid-cavernous fistula
}

result from increased intrasellar pressure, preexisting deficits from an adenoma, or destruction of the gland. . $^{3,20,59,81}$ Elevated intrasellar pressure can compress the pituitary, instigating dysfunction and producing subsequent endocrine abnormalities. Lack of recognition of endocrine perturbations can significantly increase the incidence and extent of morbidity. ${ }^{19}$

Diabetes insipidus is an uncommon sequela to pituitary apoplexy; ${ }^{17,19,41,79}$ this may reflect the differential vascularization between the pituitary gland and the hypothalamus. ${ }^{8,15,45,56,60,80}$ The anterior communicating artery vascularizes the preoptic nucleus of the hypothalamus, whereas the $A_{1}$ segment of the anterior cerebral artery supplies the anterior hypothalamus and the posterior communicating artery sustains the posterior region. Conversely, the SHA supplies the anterior lobe of the pituitary gland and the infundibulum as the IHA furnishes blood to the posterior lobe. The bilateral SHAs divide into the hypophysial portal system at the infundibulum and are joined by the ipsilateral and contralateral branches of the IHA. ${ }^{60,65}$ The hypophysial portal system supplies the anterior lobe of the pituitary. ${ }^{45}$

Diabetes insipidus has been postulated to occur as a result of impingement on the intracavernous portion of the IHA, causing diminished perfusion to the posterior lobe. ${ }^{45}$ Alternatively, kinking or pressure on the infundibulum by edematous, hemorrhagic material, which impedes transit of antidiuretic hormone from the preoptic and paraventricular nuclei of the hypothalamus, may prove to be the originating cause of DI.

Computerized tomography scans may reveal the hyperdensity of acute hemorrhage if obtained within 3 or 4 days after the event or demonstrate the mixed density of acute blood and hypodense necrotic tissue (Fig. 1). ${ }^{84}$ Subarachnoid hemorrhage may be evident if blood has invaded the basal cisterns. ${ }^{11,21,28,81}$ The greater sensitivity, precision, and tissue definition of MR imaging usually reveal the heterogeneous intensity of hemorrhage, edematous pituitary gland, and necrotic tumor, leading more readily to a diagnosis..$^{23,47,58}$ The multiplanar capability of this type of imaging allows meticulous characterization of the extent of necrosis and/or hemorrhage in addition to an evaluation of the relationship of hemorrhage and denuded tissue to neurovascular structures (Fig. 2). ${ }^{53,58-60}$

In their study of 37 patients with a diagnosis of pituitary

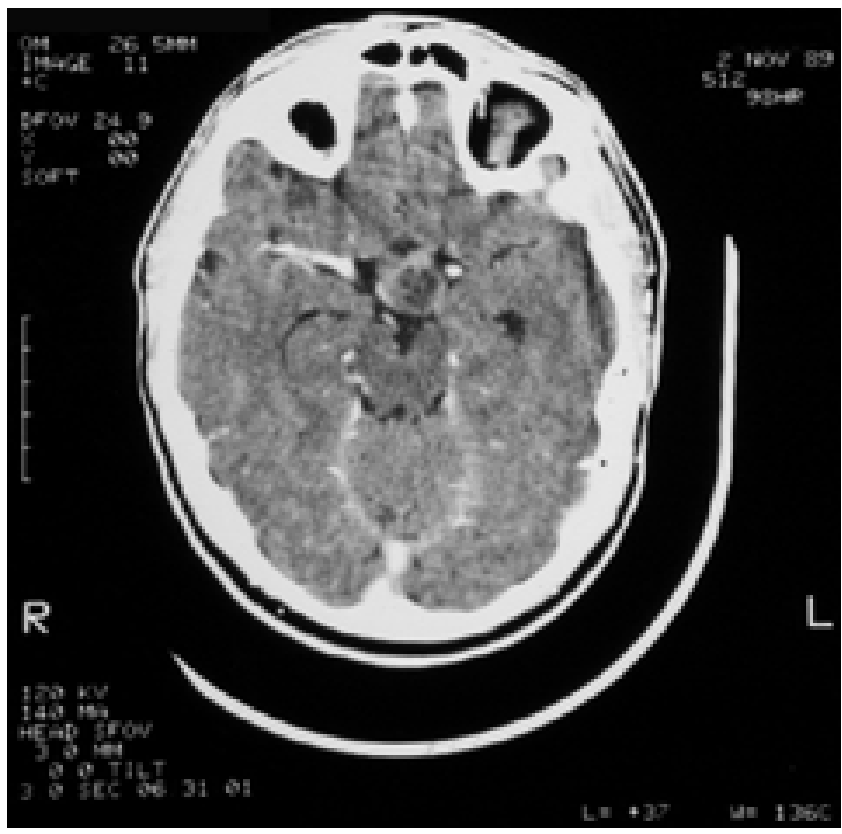

Fig. 1. Contrast-enhanced CT scan demonstrating a central region of suprasellar hypodensity with a peripheral rim of high-intensity signal, indicating a residual pituitary gland or tumor enhancement.

tumor apoplexy, Bills and colleagues ${ }^{8}$ reported a $46 \%$ detection rate of apoplexy on CT scans compared with hemorrhage or infarction ascertained using MR images in all patients thus studied. Randeva, et al., ${ }^{59}$ reported that CT scans revealed $21 \%$ of the cases of pituitary tumor apoplexy in their series of 35 patients, whereas MR images demonstrated $100 \%$ of the cases. Although MR imaging has emerged as the most exact and definitive imaging modality in this circumstance, it remains important to recognize apoplexy on CT scans if hemorrhage or necrosis is apparent, as CT scans are often obtained initially when patients present to emergency departments with nonspecific neurological complaints. Considering the low sensitivity of CT scanning in these cases, it is important not to ignore or reject the possibility of pituitary tumor apoplexy if clinical assessment indicates this diagnosis.

Cerebrospinal fluid analysis is rarely helpful in establishing a diagnosis because the fluid may be clear if blood has not broached the subarachnoid space. Alternatively, CSF may be bloody or xanthochromic, depending on the time interval from the ictus. ${ }^{8,59,65,80}$ (Yellow-tinged CSF will be present in $90 \%$ of specimens at $>12$ hours from onset. ${ }^{30}$ ) Increased protein levels and pleocytosis noted in the CSF of some patients are similarly nondiagnostic.

\section{PRECIPITATING FACTORS AND TUMOR CHARACTERISTICS}

Predisposing factors have been identified in approximately $50 \%$ of cases of pituitary tumor apoplexy. ${ }^{4,9,19,53}$ Head trauma, ${ }^{33,77,80}$ bromocriptine administration or withdrawal, ${ }^{86}$ anticoagulation, ${ }^{50,51}$ pregnancy, cardiac bypass, ${ }^{55,68,71}$ bowel or other general surgery, ${ }^{85}$ atherosclerosis, diabetic ketoacidosis, ${ }^{12,15,20}$ estrogen therapy, ${ }^{15}$ radia- 

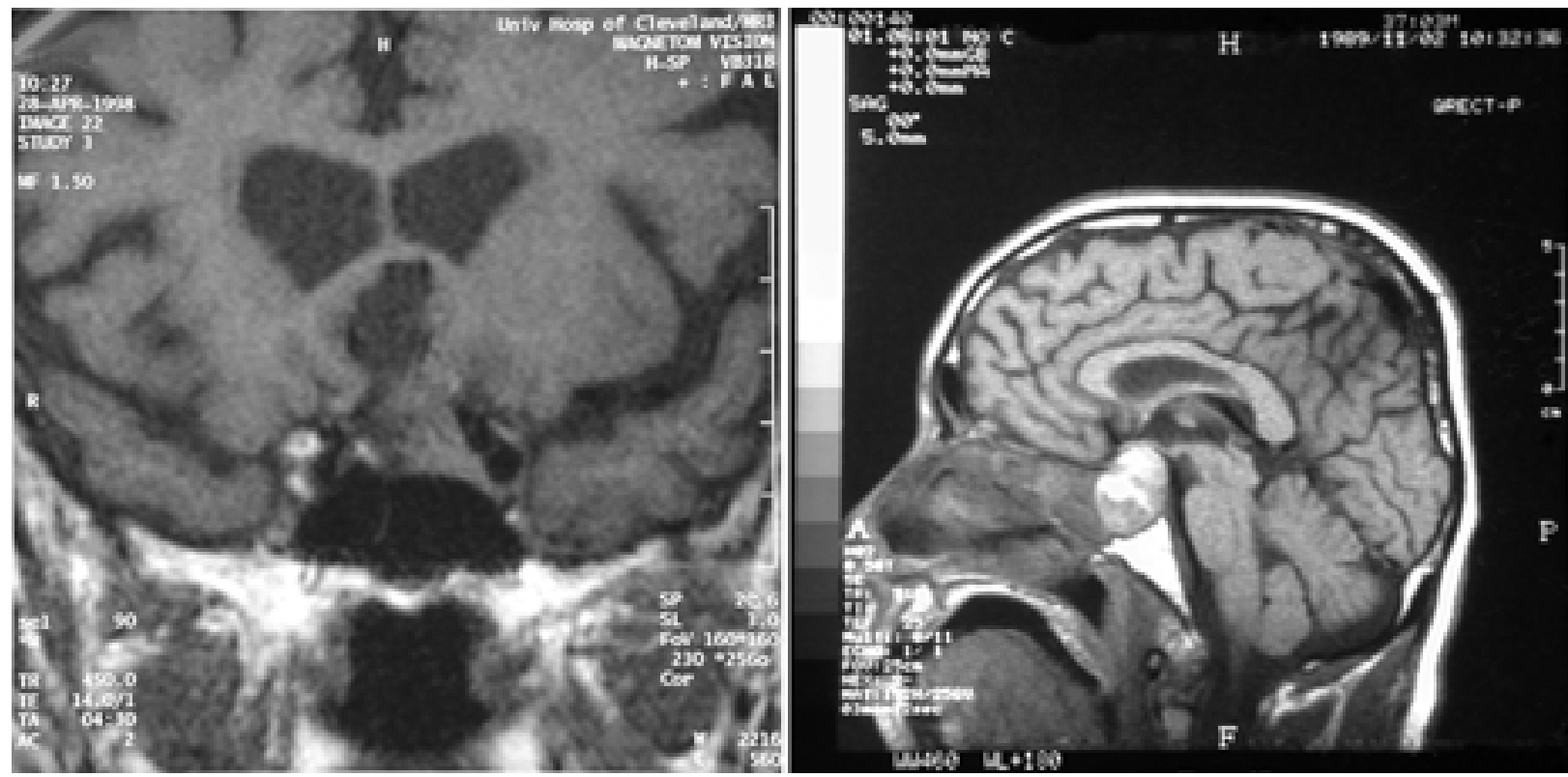

Fig. 2. Left: Unenhanced coronal $\mathrm{T}_{1}$-weighted $\mathrm{MR}$ image revealing a sellar and suprasellar adenoma with an area of central necrosis. Right: Unenhanced sagittal $\mathrm{T}_{1}$-weighted $\mathrm{MR}$ image obtained in another patient demonstrating heterogeneous areas of high-intensity signals mixed with regions of lower signals indicating subacute hemorrhage within a lesion.

tion therapy, ${ }^{12,49}$ hypertension, ${ }^{58,78}$ and hypotension have been cited as inciting apoplectic episodes. Pituitary apoplexy has also been instigated by dynamic testing with thyrotropin-releasing hormone, gonadotropin-releasing hormone, and corticotropin-releasing factor. ${ }^{4,9,16,22,41,52,61,66,78}$

Biousse and associates ${ }^{9}$ reported increased demand on the pituitary coupled with blood pressure fluctuations as an inciting factor in the generation of pituitary tumor apoplexy. Fluctuations in blood pressure associated with cardiac bypass and surgical interventions may provoke necrosis. Fragmentation of atherosclerotic plaques with lodging of particles within the pituitary vasculature may potentiate gland infarction. ${ }^{73}$ The association of pituitary tumor apoplexy with surgery, childbirth, and infection may reflect the greater activity of the pituitary gland in response to the increased need for stress hormones in these circumstances. ${ }^{9}$ Additionally, estrogen therapy and pregnancy stimulate and enhance the demand on the pituitary. ${ }^{21,75}$ Sneezing, coughing, and severe acidosis elicit alterations in blood flow or an abnormal osmotic composition of blood delivered to the pituitary. ${ }^{9}$ Administration of releasing hormones during stimulation tests may increase intratumoral blood flow and provoke bleeding in friable, immature vessels. . $^{41,66}$

Numerous investigators have reported a greater propensity toward necrosis and hemorrhage in larger tumors due to the discrepancy between the rate of neoplastic progression and the availability of circulatory input. ${ }^{19,24,25,46,49}$, $56,70,80$ Nevertheless, small tumors also hemorrhage. ${ }^{50,80}$ The inherent fragility of the vascular infrastructure of tumors may provide an explanation for hemorrhage in these instances. ${ }^{15,24,32}$ Predisposing factors may also prove more important in the genesis of necrosis and/or hemorrhage in smaller lesions. Ebersold, et al., ${ }^{24}$ have emphasized vascular stasis and subsequent thrombosis as the likely mechanism eliciting necrosis and subsequent bleeding.
Impingement of the SHA from compression of the pituitary stalk and superior hypophysial vessels against a dilated or more closely maintained diaphragma sella is cited as placing pituitary adenomas at high risk for ischemia and ensuing hemorrhage. ${ }^{15,59,65}$ Yet it has been suggested that tumor vessels originate from the IHA. ${ }^{15,59}$ Attenuation in the caliber of the lumen of feeding vessels from the SHA would thus place the basis of the apopleptic event within the anterior lobe of the pituitary, rather than within the tumor itself. ${ }^{15,59}$

There is no preponderance of tumor type in the genesis or evolution of pituitary tumor apoplexy. Although adenomas are most commonly implicated in apoplectic events, necrosis and/or hemorrhage has been noted to occur in Rathke cleft cysts, ${ }^{54}$ in nontumorous pituitary glands, ${ }^{17,60}$ and in association with an empty sella turcica. ${ }^{2}$ Although clinically evident apoplexy has commonly been deemed to occur in less than $10 \%$ of pituitary adenomas, the incidence of subclinical hemorrhage has been identified in as many as $28 \%$ of histologically scrutinized tumors. ${ }^{25,26} \mathrm{In}$ their retrospective review of 560 cases of pituitary adenoma, Wakai, et al., ${ }^{81}$ found 93 tumors $(16.6 \%)$ with evidence of degenerated blood or intratumoral hematoma, yet only 38 patients $(6.8 \%)$ with pituitary lesions experienced an apoplectic event. Similarly, in his examination of specimens obtained from 280 patients, Deb ${ }^{21}$ identified 48 patients $(17.1 \%)$ in whom hemorrhage was discovered at surgery, whereas only 15 patients $(5.4 \%)$ demonstrated clinically evident symptoms or signs.

Comprising only $10 \%$ of intracranial neoplasms ${ }^{69}$ pituitary adenomas constitute a greater proportion of tumorrelated hemorrhages. ${ }^{17}$ In considering intracranial hemorrhage derived from tumors, Glass and $\mathrm{Abbott}^{28}$ reported that $25 \%$ of intracranial hemorrhages originated secondary to adenomas compared with $50 \%$ instigated by gliomas, which are five times more common. Based on their 
examination of 1861 hemorrhagic intracranial tumors, Wakai, et al., ${ }^{82}$ discovered that adenomas are 5.4 times more likely to bleed.

\section{TREATMENT}

The pituitary gland remains capable of secreting adequate amounts of hormones when as little as $10 \%$ of residual tissue remains; however, a dearth or absence of sufficient hormone can lead to adrenal crisis. ${ }^{15,19,43,56,58,80}$ The prompt recognition of apoplexy permits the immediate initiation of steroid replacement. ${ }^{5,53}$ One hundred milligrams of hydrocortisone should be administered intravenously on establishment of the correct diagnosis. ${ }^{40,70}$

The definitive treatment for pituitary tumor apoplexy is surgery for decompression of constricted cavernous and/or suprasellar structures, especially in cases in which visual acuity or field defects, decreased level of consciousness, or progressive deterioration of visual or oculomotor abilities are present. . $^{15,19,25,39,44,53,58,65,80}$ Expeditious surgical intervention is recommended by most authors. ${ }^{8}$, $19,24,25,37,44,47,53,82$

The transsphenoidal route is adequate in most instances. ${ }^{21,24,53}$ An intracranial approach may be recommended in cases in which there is a significant hemispheric extension of hemorrhage, the presence of hemorrhage and/or necrosis extending distal to a severely constricted diaphragma sella, or the existence of a poorly aerated sphenoid sinus. ${ }^{15,53,83}$ Use of the intracranial route to reach suprasellar sites of hemorrhagic and necrotic material places the delicate perforating vessels extending from the anterior communicating artery and the SHA at risk.

A significant visual compromise, diminished level of consciousness, and declining visual status are clear indications for operative intervention. ${ }^{15,65,79}$ Surgery offers a means for direct and immediate decompression and optimizes the chance for restitution of endocrine function and recovery of neural elements. ${ }^{5,59}$ In addition, surgery allows tumor resection, decreasing the chance of continued neoplastic viability. ${ }^{53}$ Extensive intracavernous extension or invasion limit the opportunity for complete tumor removal.

In a minority of published papers, cases of isolated and stable meningismus and/or ophthalmoplegia have been shown to be managed medically, because meningismus will resolve once blood no longer irritates the dura mater and ophthalmoplegia can resolve spontaneously. ${ }^{22,44,56,60,76}$ Medical management includes close monitoring of endocrine, neurological, and ophthalmological function, hormone administration, and support with intravenous fluids and electrolytes.

In our own experience with 15 patients who presented with signs and symptoms indicative of pituitary tumor apoplexy, surgical decompression within 2.2 days after symptom onset led to the postoperative return of endocrine function in 11 patients. This recovery leads us to believe that the source of pituitary compromise in the wake of apoplexy, in some cases, is compression rather than destruction, and that in certain patients there remains the chance for improvement of function. ${ }^{3,5}$ Of course, if the apoplectic event involves overt gland necrosis or ischemia from attenuation of the caliber of the SHA, return of function would be less likely. Still, in light of our data, the potential for restitution of pituitary activity is another reason for advocating timely surgical intervention.

The unpredictable clinical course of pituitary tumor apoplexy provides a strong rationale for prompt decompression. $9,15,19,22,56,58,60,80$ The capricious nature of pituitary tumor apoplexy makes it difficult or impossible to foretell precisely in which patients the physical conditions will remain stable and in which it will deteriorate. It is impossible comfortably to exclude patients from surgical intervention by speculating that their conditions will remain stable.

\section{PATIENT OUTCOMES}

Among visual perturbations, abnormalities in optic motility generally rebound quickly once the third, fourth, and sixth cranial nerves are relieved of compression. $3,5,15,20,21,46,47,56,59,80$ Congruous eye movements are more readily restored than the chiasmal and optic nerve defects of decreased visual acuity and restriction of visual fields. ${ }^{15,25,56,70,80}$ In their series of 37 patients, Bills and colleagues ${ }^{8}$ reported that ocular paresis was resolved in $100 \%$, visual field deficits in $95 \%$, and deficits in acuity in $88 \%$ of patients. This pattern of resolution or improvement is reflected in numerous other studies. ${ }^{59,80}$ Similarly, patients in whom decompression is accomplished expeditiously generally experience greater improvements in both cranial nerve and chiasmal deficits. ${ }^{14,58,59,68}$ Bills and colleagues also described the largest recovery in patients who underwent surgery within 1 week after inception of signs and symptoms.

More than half of affected patients require hormone replacement following an episode of pituitary tumor apoplexy. ${ }^{3,8,42,47,56,59,79}$ In their study of 37 patients, Bills and colleagues reported that administration of steroid, thyroxine, and testosterone was essential postoperatively in 82, 89 , and $64 \%$ of patients, respectively. From their review of the literature, Veldhuis and Hammond ${ }^{79}$ ascertained that, following an episode of pituitary tumor apoplexy, $88 \%$ of patients lacked sufficient growth hormone, $76 \%$ adequate amounts of lutenizing hormone, $67 \%$ sufficient prolactin, and $66 \%$ enough adrenocorticotropic hormone, and that $33 \%$ of patients experienced deficiencies in estradiol. Diabetes insipidus occurred in only 2 to $3 \%$ of patients examined for this disorder. ${ }^{79}$

Despite these outcomes, as mentioned previously, by performing surgical decompression within 3 days after symptom onset, we were able to produce a return of endocrine function in 11 of 15 patients. Restitution of pituitary function was recognized within 3 days after surgery by the return of endogenous adrenocorticotropin hormone secretion.

\section{CONCLUSIONS}

Pituitary tumor apoplexy is most commonly a discrete event marked by onset of the constellation of severe, sudden headache, restriction of visual fields, and paresis of ocular muscles. Signs and symptoms generally arise consequent to the following: 1) endocrine abnormalities from acute pituitary dysfunction; 2) subarachnoid extravasation of blood and dural irritation; and 3) cranial nerve or hemi- 
spheric compression from lateral or superior extension of necrotic and/or hemorrhagic material. Clinical indications associated with neuroimaging and surgical or pathological findings constitute the syndrome of pituitary apoplexy. The variable presentation of nonspecific signs and symptoms can mimic numerous other causes, including meningitis, midbrain infarction, and cavernous sinus thrombosis; the dramatic onset may resemble that of a ruptured intracranial aneurysm.

Pituitary macroadenomas are most commonly implicated as the entity underlying the ictus. Although pituitary tumor apoplexy most commonly occurs spontaneously, numerous precipitating associations have been described, including bromocriptine therapy, pregnancy, and hypertension. Abrupt expansion of a pituitary lesion causes incipient pressure on intrasellar and parasellar structures, producing clinical signs referable to the size and contour of necrotic and/or hemorrhagic material. Magnetic resonance imaging most accurately identifies this pathological condition, precisely defines its extent, and establishes its proximity to neurovascular elements.

Swift recognition of an accurate diagnosis allows prompt steroid administration and surgical decompression, which is most commonly accomplished via the transsphenoidal approach. Although hypopituitarism is a prominent finding preoperatively among patients following an apopleptic episode, an improvement in endocrine function has been attained in some patients. Long-term hormone replacement in some axes is required in a majority of patients. Recovery of visual and optomotor symptoms is commonly realized, with paresis of ocular muscles showing the most invariable improvement, especially in cases in which surgery is performed within 1 week after clinical onset.

\section{References}

1. Ahmed M, al-Jurf M: Pituitary apoplexy revisted. Arch Intern Med 153:2165-2168, 1993

2. Alatakis S, Malham GM, Fabinyi GC: Spontaneous haemorrhage into an empty sella turcica mimicking pituitary apoplexy. J Clin Neurosci 7:557-560, 2000

3. Arafah BM, Harrington JF, Madhoun ZT, et al: Improvement of pituitary function after surgical decompression for pituitary tumor apoplexy. J Clin Endocrinol Metab 71:323-328, 1990

4. Arafah BM, Taylor HC, Salazar R, et al: Apoplexy of a pituitary adenoma after dynamic testing with gonadotropin-releasing hormone. Am J Med 87:103-105, 1989

5. Arafah BM, Ybarra J, Tarr RW, et al: Pituitary tumor apoplexy: pathophysiology, clinical manifestations, and management. J Int Care Med 12:123-134, 1997

6. Bailey P: Pathological report of a case of akromegaly, with especial reference to the lesions in the hypophysis cerebri and in the thyroid gland: and a case of hemorrhage into the pituitary. Philadelphia Med J 1:789-792, 1898

7. Basaria S, Turchin A, Krasner A: Apoplexy in a recurrent pituitary adenoma. Postgrad Med J 77:23, 2001

8. Bills DC, Meyer FB, Laws ER Jr, et al: A retrospective analysis of pituitary apoplexy. Neurosurgery 33:602-609, 1993

9. Biousse V, Newman NJ, Oyesiku NM: Precipitating factors in pituitary apoplexy. J Neurol Neurosurg Psychiatry 71: 542-545, 2001

10. Bleibtreu L: Ein Fall von Akromegalie (Zerstörung der Hypophysis durch Blutung). Munch Med Wochenschr 43: 2079-2080, 1905

11. Bonicki W, Kasperlik-Zaluska A, Koszewski W, et al: Pituitary apoplexy: endocrine, surgical and oncological emergency. Incidences, clinical course and treatment with reference to 799 cases of pituitary adenomas. Acta Neurochir 120:118-122, 1993

12. Brennan CF, Malone RG, Weaver JA: Pituitary necrosis in diabetes mellitus. Lancet 261:12-16, 1956

13. Brougham M, Heusner AP, Adams RD: Acute degenerative changes in adenomas of the pituitary body-with special reference to pituitary apoplexy. J Neurosurg 7:421-439, 1950

14. Canton A, Simo R, Gil L, et al: Headache, vomiting and diplopia. Postgrad Med J 73:357-359, 1997

15. Cardoso ER, Peterson EW: Pituitary apoplexy: a review. Neurosurgery $14: 363-373,1984$

16. Chapman AJ, Williams G, Hockley AD, et al: Pituitary apoplexy after combined tests of anterior pituitary function. $\mathbf{B r}$ Med J 291:26-29, 1985

17. Conomy JP, Ferguson JH, Brodkey JS, et al: Spontaneous infarction in pituitary tumors: neurologic and therapeutic aspects. Neurology 25:580-587, 1975

18. Cushing H: Tumors of the Nervus Acusticus and the Syndrome of the Cerebellopontile Angle. Philadelphia: WB Saunders, 1917, p 190

19. da Motta LA, de Mello PA, de Lacerda CM, et al: Pituitary apoplexy. Clinical course, endocrine evaluations and treatment analysis. J Neurosurg Sci 43:25-36, 1999

20. David NJ, Gargano FP, Glaser JS: Pituitary apoplexy in clinical perspective, in Glaser JS (ed): Neuro-ophthalmology. St Louis: Mosby, 1978, pp 140-165

21. Deb S: Clinical significance of pituitary apoplexy. J Indian Med Assoc 96:302-307, 1998

22. Dokmetas HS, Selcuklu A, Colak R, et al: Pituitary apoplexy probably due to TRH and GnRH stimulation tests in a patient with acromegaly. J Endocrinol Invest 22:698-700, 1999

23. Dulipsingh L, Lassman MN: Images in Clinical Medicine. Pituitary apoplexy. N Engl J Med 342:550, 2000

24. Ebersold MJ, Laws ER Jr, Scheithauer BW, et al: Pituitary apoplexy treated by transsphenoidal surgery. A clinicipathological and immunocytochemical study. J Neurosurg 58:315-320, 1983

25. Epstein S, Pimstone BL, de Villiers JC, et al: Pituitary apoplexy in five patients with pituitary tumours. Br Med J 2:267-270, 1971

26. Famularo G, Pozzessere C, Piazza G, et al: Abrupt-onset oculomotor paralysis: an endocrine emergency. Eur J Emerg Med 8:233-236, 2001

27. Findling JW, Tyrrell JB, Aron DC, et al: Silent pituitary apoplexy: subclinical infarction of an adrenocorticotropin-producing pituitary adenoma. J Clin Endocrinol Metab 52:95-97, 1981

28. Glass B, Abbott KH: Subarachnoid hemorrhage consequent to intracranial tumors; review of literature and report of seven cases. Arch Neurol Psychiatry 73:369-379, 1955

29. Glendenning P, Pullan PT, Knuckey NW: Pituitary apoplexy: the importance of citing the differential diagnosis. Med J Aust 173:548-549, 2000

30. Greenberg MS: Handbook of Neurosurgery, ed 3. Lakeland, FL: Greenberg Graphics, 1994, p 140

31. Gutin PH, Cushard WG Jr, Wilson CB: Cushing's disease with pituitary apoplexy leading to hypopituitarism, empty sella, and spontaneous fracture of the dorsum sellae. Case report. J Neurosurg 51:866-869, 1979

32. Hirano A, Tomiyasu U, Zimmerman HM: The fine structure of blood vessels in chromophobe adenoma. Acta Neuropathol 22:200-207, 1972

33. Holness RO, Ogundimu FA, Langille RA: Pituitary apoplexy following closed head trauma. Case report. J Neurosurg 59: 677-679, 1983

34. Inamasu J, Hori S, Sekine K, et al: Pituitary apoplexy without ocular/visual symptoms. Am J Emerg Med 19:88-90, 2001 
35. Jefferson G: Extrasellar extensions of pituitary adenomas. Proc Roy Soc Med 33:433-458, 1940

36. Kaiser UB, Hedley-Whyte ET: Case 15-2001-a 72-year-old man with persistent fever and hypotension. N Engl J Med 344: 1536-1542, 2001

37. Kamiya Y, Jin-No Y, Tomita K, et al: Recurrence of Cushing's disease after long-term remission due to pituitary apoplexy. Endocr J 47:793-797, 2000

38. Kovacs K: Necrosis of the anterior pituitary in humans. I. Neuroendocrinology 4:170-199, 1969

39. Lange M, Woenckhaus M, Segiet W, et al: A rare fatal course of disease in a patient with spontaneous pituitary apoplexy. Case report and literature review. Neurosurg Rev 22:163-169, 1999

40. Lee CC, Cho AS, Carter WA: Emergency department presentation of pituitary apoplexy. Am J Emerg Med 18:328-331, 2000

41. Levy A: Hazards of dynamic testing of pituitary function. Clin Endocrinol 58:543-544, 2003

42. Lewin IG, Mohan J, Norman PF, et al: Pituitary apoplexy. BMJ 297:1526-1527, 1988

43. Lindholm J, Bjerre P, Riishede J, et al: Pituitary function in patients with evidence of spontaneous disappearance of a pituitary adenoma. Clin Endocrinol 18:599-603, 1983

44. Maccagnan P, Macedo CL, Kayath MJ, et al: Conservative management of pituitary apoplexy: a prospective study. J Clin Endocrinol Metab 80:2190-2197, 1995

45. McConnell EM: The arterial blood supply of the human hypophysis cerebri. Anat Rec 115:175-203, 1953

46. McFadzean RM, Doyle D, Rampling R, et al: Pituitary apoplexy and its effect on vision. Neurosurgery 29:669-675, 1991

47. Milazzo S, Toussaint P, Proust F, et al: Ophthalmologic aspects of pituitary apoplexy. Eur J Ophthalmol 6:69-73, 1996

48. Mizutani T, Teramoto A, Aruga T, et al: Prepubescent pitui-tary null cell macroadenoma with silent macroscopic apoplexy: case report. Neurosurgery 33:907-910, 1993

49. Mohanty S, Tandon PN, Banerji AK, et al: Haemorrhage into pituitary adenomas. J Neurol Neurosurg Psychiatry 40: 987-991, 1977

50. Mohr G, Hardy J: Hemorrhage, necrosis, and apoplexy in pituitary adenomas. Surg Neurol 18:181-189, 1982

51. Nourizadeh AR, Pitts FW: Hemorrhage into pituitary adenoma during anticoagulant therapy. JAMA 193:623-625, 1965

52. O'Sullivan ST, Vaughan CJ, Galvin RJ, et al: Pituitary apoplexy after stimulation tests. Postgrad Med J 71:123, 1995 (Letter)

53. Onesti ST, Wisniewski T, Post KD: Clinical versus subclinical pituitary apoplexy: presentation, surgical management, and outcome in 21 patients. Neurosurgery 26:980-986, 1990

54. Pawar SJ, Sharma RR, Lad SD, et al: Rathke's cleft cyst presenting as pituitary apoplexy. J Clin Neurosci 9:76-79, 2002

55. Peck V, Lieberman A, Pinto R, et al: Pituitary apoplexy following open-heart surgery. N Y State J Med 80:641-643, 1980

56. Pelkonen R, Kuusisto A, Salmi J, et al: Pituitary function after pituitary apoplexy. Am J Med 65:773-778, 1978

57. Peter SA: Subclinical pituitary apoplexy. N Y State J Med 86: 656-657, 1986

58. Piotin M, Tampieri D, Rufenacht DA, et al: The various MRI patterns of pituitary apoplexy. Eur Radiol 9:918-923, 1999

59. Randeva HS, Schoebel J, Byrne J, et al: Classical pituitary apoplexy: clinical features, management and outcome. Clin Endocrinol 51:181-188, 1999

60. Reid RL, Quigley ME, Yen SS: Pituitary apoplexy. A review. Arch Neurol 42:712-719, 1985

61. Riedl M, Clodi M, Kotzmann H, et al: Apoplexy of a pituitary macroadenoma with reversible third, fourth and sixth cranial nerve palsies following administration of hypothalamic releasing hormones: MR features. Eur J Radiol 36: 1-4, 2000

62. Robinson R, Toland J, Eustace P: Pituitary apoplexy: a cause for painful third nerve palsy. Neuroophthalmology 10: 257-260, 1990
63. Rogg JM, Tung GA, Anderson G, et al: Pituitary apoplexy: early detection with diffusion-weighted MR imaging. AJNR 23:1240-1245, 2002

64. Rosenbaum TJ, Houser OW, Laws ER: Pituitary apoplexy producing internal carotid artery occlusion. Case report. J Neurosurg 47:599-604, 1977

65. Rovit RL, Fein JM: Pituitary apoplexy: a review and reappraisal. Case report. J Neurosurg 37:280-288, 1972

66. Sanno N, Ishii Y, Sugiyama M, et al: Subarachnoid haemorrhage and vasospasm due to pituitary apoplexy after pituitary function tests. Acta Neurochir 141:1009-1010, 1999

67. Saul RF, Hilliker JK: Third nerve palsy: the presenting sign of a pituitary adenoma in five patients and the only neurological sign in four patients. J Clin Neuroophthalmol 5:185-193, 1985

68. Savage EB, Gugino L, Starr PA: Pituitary apoplexy following cardiopulmonary bypass: considerations for a staged cardiac and neurosurgical procedure. Eur J Cardiothorac Surg 8: 333-336, 1994

69. Scheithauer BW: The pituitary and sellar region, in Sternberg SS (ed): Diagnostic Surgical Pathology. New York: Raven Press, 1989, Vol 1, pp 371-393

70. Seyer H, Kömpf D, Fahlbusch R: Optomotor palsies in pituitary apoplexy. Neuroophthalmology 12:217-224, 1992

71. Shapiro LM: Pituitary apoplexy following coronary artery bypass surgery. J Surg Oncol 44:66-68, 1990

72. Shimon I, Melmed S: Management of pituitary tumors. Ann Intern Med 129:472-483, 1998

73. Sussman EB, Porro RS: Pituitary apoplexy: the role of atheromatous emboli. Stroke 5:318-323, 1974

74. Symonds C: Ocular palsy as the presenting symptom of pituitary adenoma. Bull Johns Hopkins Hosp 111:72-82, 1962

75. Tiboldi T, Nemessányi Z, Csernay I, et al: Effect of estrogenon pituitary blood flow in rats. Endocrinol Exp 2:73-77, 1967 (Reference unverified)

76. Tsitsopoulos P, Andrew J, Harrison MJ: Pituitary apoplexy and haemorrhage into adenomas. Postgrad Med J 62:623-626, 1986

77. VanWagenen WP: Haemorrhage into a pituitary tumor following trauma. Ann Surg 95:625-628, 1932

78. Vassallo M, Rana Z, Allen S: Pituitary apoplexy after stimulation tests. Postgrad Med J 70:444-445, 1994

79. Veldhuis JD, Hammond JM: Endocrine function after spontaneous infarction of the human pituitary: report, review, and reappraisal. Endocr Rev 1:100-107, 1980

80. Vidal E, Cevallos R, Vidal J, et al: Twelve cases of pituitary apoplexy. Arch Intern Med 152:1893-1899, 1992

81. Wakai S, Fukushima T, Teramoto A, et al: Pituitary apoplexy: its incidence and clinical significance. J Neurosurg 55: 187-193, 1981

82. Wakai S, Yamakawa K, Manaka S, et al: Spontaneous intracranial hemorrhage caused by brain tumor: its incidence and clinical significance. Neurosurgery 10:437-444, 1982

83. Wilson CB, Dempsey LC: Transsphenoidal microsurgical removal of 250 pituitary adenomas. J Neurosurg 48:13-22, 1978

84. Wright RL, Ojemann RG, Drew JH: Hemorrhage into pituitary adenomata. Report of two cases with spontaneous recovery. Arch Neurol 12:326-331, 1965

85. Yahagi N, Nishikawa A, Matsui S, et al: Pituitary apoplexy following cholecystectomy. Anaesthesia 47:234-236, 1992

86. Yamaji T, Ishibashi M, Kosaka K, et al: Pituitary apoplexy in acromegaly during bromocriptine therapy. Acta Endocrinol 98: $171-177,1981$

Manuscript received February 27, 2004.

Accepted in final form March 16, 2004.

Address reprint requests to: Meg Verrees, M.D., Department of Neurosurgery, Case Western Reserve University, University Hospitals of Cleveland, 11000 Euclid Avenue, Cleveland, Ohio 44106. email: megverrees@yahoo.com. 